\title{
Advanced Technologies and Mechanisms for Yeast Evolutionary Engineering
}

\author{
Hong-Yeoul Ryu* \\ School of Life Sciences, BK21 Plus KNU Creative BioResearch Group, College of National Sciences, Kyungpook National University, \\ Daegu 41566, Republic of Korea
}

Received: September 7, 2020 / Revised: October 9, 2020 / Accepted: October 11, 2020

\begin{abstract}
In vitro evolution is a powerful technique for the engineering of yeast strains to study cellular mechanisms associated with evolutionary adaptation; strains with desirable traits for industrial processes can also be generated. There are two distinct approaches to generate evolved strains in vitro: the sequential transfer of cells in the stationary phase into fresh medium or the continuous growth of cells in a chemostat bioreactor via the constant supply of fresh medium. In culture, evolutionary forces drive diverse adaptive mechanisms within the cell to overcome environmental or intracellular stressors. Especially, this engineering strategy has expanded to the field of human cell lines; the understanding of such adaptive mechanisms provides promising targets for the treatment of human genetic diseases and cancer. Therefore, this technology has the potential to generate numerous industrial, medical, and academic applications.
\end{abstract}

Keywords: Evolutionary engineering, in vitro evolution, yeast, adaptive mechanisms, gene therapy

\section{Introduction}

Yeast is one of the most important micro-organisms in the scientific fields of biotechnology, biomedicine, and drug discovery [1]. Yeast cells have many biological advantages for industrial applications, such as high genetic amenability, low cost for cell culturing, and relatively quick cell division cycles [2]. There are two distinct engineering strategies to study the function of genes and develop industrial strains with improved capacity for stress resistance or production of value-added compounds [3]. First strategy uses gene manipulation techniques to permanently alter the genetic makeup through insertion, mutation, or deletion, which include recombination-mediated genetic engineering, clustered regularly interspaced short palindromic repeats, or error-

\section{*Corresponding author}

Tel: +82-53-950-6352, Fax: +82-53-943-2762

E-mail: rhr4757@knu.ac.kr

(c) 2020, The Korean Society for Microbiology and Biotechnology prone polymerase chain reaction (PCR). The second approach employs in vitro evolution under the selective pressure of genetic or environmental stressors to identify strains with high tolerance to the stressful stimuli in an unbiased fashion.

While genetic engineering is a classical method to introduce targeted or intended genetic variation into a strain, evolutionary engineering exploits the interesting feature of yeast cells to rapidly adapt to genetic or environmental changes [4]. These adaptations to re-establish homeostasis and maintain viability from the acute stress conditions appear changes in diverse cellular pathways [5]. When these responses are not sufficient to protect cells from stress, yeast activate second-line adaptive mechanisms that introduce genetic changes to confer resistance to the stress [6]. Biotechnology typically use this adaptive laboratory evolution to biosynthesize new desirable products, improve production yields, or reduce costs in industrial processes [7]. The present review provides an overview of the evolutionary engineering of 


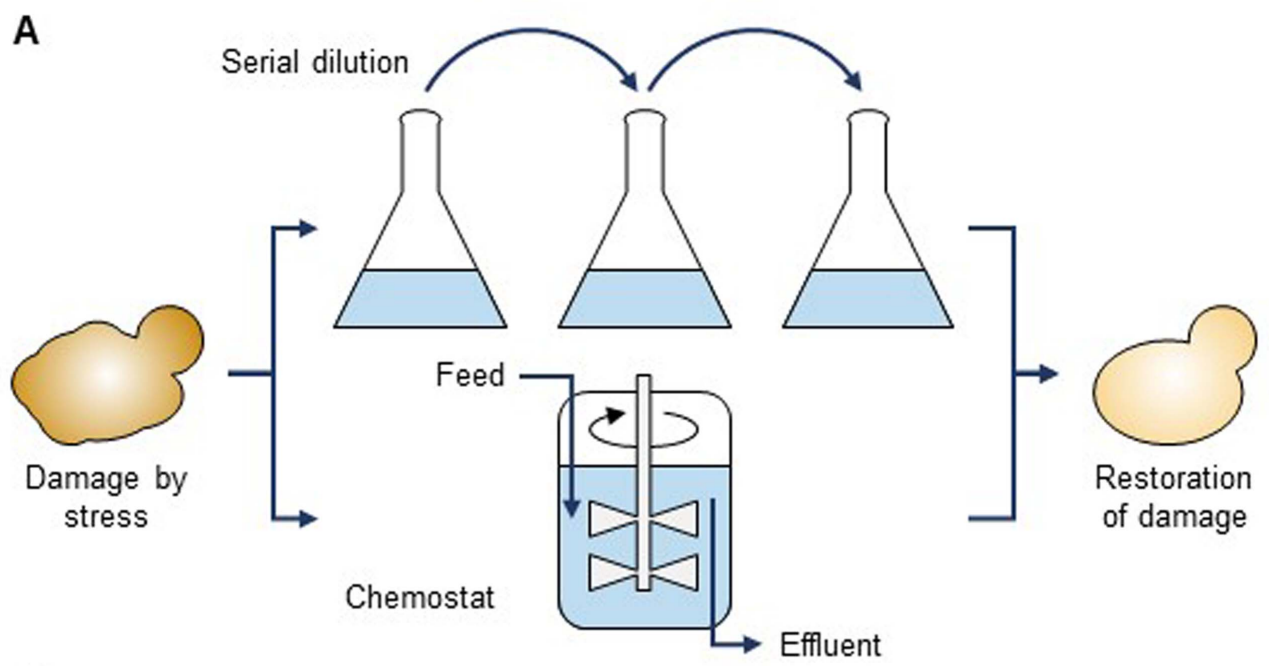

B

In vitro yeast evolution

\begin{tabular}{|c|c|}
\hline $\begin{array}{c}\text { First-line adaptive } \\
\text { mechanisms }\end{array}$ & $\begin{array}{c}\text { Second-line adaptive } \\
\text { mechanisms }\end{array}$ \\
\hline $\begin{array}{l}\text { Changes: } \\
\text { - Metabolism } \\
\text { - Gene expression } \\
\text { - Cell cycle progression } \\
\text { - Protein homeostasis } \\
\text { - Cytoskeletal organization } \\
\text { - Vesicular trafficking } \\
\text { - Enzyme activity } \\
\text { - Epigenetics }\end{array}$ & $\begin{array}{l}\text { - Mutation } \\
\text { - Gene amplification } \\
\text { - Transposition } \\
\text { - Multisite heterozygosity } \\
\text { and mosaicism } \\
\text { - Aneuploidy and } \\
\text { polyploidy } \\
\text { - Mistranslation }\end{array}$ \\
\hline
\end{tabular}

Fig. 1. Use of in vitro evolution methods to study adaptive mechanisms in yeast. (A) Two technical strategies of in vitro evolution: serial transfer and chemostat culture systems. Serial transfer propagates yeast in parallel serial cultures by doing sequential passages of cells (via dilution) once they have grown to stationary phase. Chemostat culturing keeps yeast cell numbers continuously growing in bioreactors while providing fresh medium. (B) Adaptive mechanisms of yeast during laboratory evolution culture.

yeasts for food/industrial biotechnology and the development of medical therapy.

\section{Evolutionary engineering strategies}

In vitro evolution is a general method to artificially induce cellular or genetic changes under specific growth conditions that are difficult to produce in nature, and therefore provides insights into the understanding of the molecular adaptation to the environmental change [7]. Usually, there are two main approaches in isolating evolutionary engineered cells that survive to the stressinduced conditions imposed by in vitro evolution [3] (Fig. 1A). First approach uses sequential passages of cells in shaking flasks or tubes to propagate yeast in parallel serial cultures. These cells are grown to stationary phase in a specific medium prior to being diluted and transferred into fresh medium. This process is repeated periodically (e.g., daily) until interesting phenotypes are acquired by the evolved cells. This method has the advantage of being low-cost and easy to operate and can also be automated to enable massively paralleled yeast cultures [8, 9]. The second approach is continuously growing cultures in chemostat bioreactors while providing fresh medium and keeping yeast cell numbers constant by reversely emitting equal amounts of effluents [10-12]. In contrast to the serial transfer culture, this technique maintains the physiological steady-state conditions of the cells and population densities and incorpo- 
rates relatively huge volumes of culture medium. Both strategies can precisely control the diverse culture conditions, such as nutrient supply, $\mathrm{pH}$, temperature, oxygenation, or drug supplementation [13-16].

Methods to shorten the required time to achieve evolution enhance profits by saving resources and labor costs. Such methods including chemical mutagens, radiation, and genetic engineering can accelerate yeast evolution by increasing mutation frequencies in evolving cultures [3]. For instance, loss of Msh2 DNA mismatch protein function led to a 40 -fold increase of mutation rate in the yeast genome, and the mec1 1 tel1 $\Delta$ double mutant yeast strain exhibited chromosomal aneuploidy with large structural variations [17]. Furthermore, the expression of specific enzymes, such as the topoisomerase Cre recombinase, DNA glycosylase Mag1, or nuclease-deficient Cas9 (dCas9), can generate diverse genetic variation during evolutionary engineering [18-21].

\section{Industrial applications of yeast evolutionary engineering}

In biotechnology and food industries, yeast strains resistant to specific stresses are useful in enhancing the processivity, quantity, and quality of production for valuable materials, baking, brewing, and fermentation [22, 23]. For example, anaerobic starvation has been extensively investigated by nitrogen- or carbon-limited chemostat systems and has provided excellent advantages in the industrial production of bread, ethanol, and alcoholic beverages [24, 25].

The changes of endogenous energy metabolism to become tolerant to such stresses are driven by not only the control of specific genes but also diverse physiological changes [22, 26]. Several studies show the strong correlation between the change of intracellular trehalose concentration and the capability to resist heat and cold shocks [27]. Typically, continuous heat stress invokes a redistribution of catabolic and anabolic fluxes related to energy metabolism and increased ribonucleic acid (RNA) content [28, 29]. Other research found ultraviolet (UV) mutagenesis during 200 freeze-thaw cycles led to freezetolerant yeast strains that keep more gassing power during frozen dough storage [30]. Targeted in vitro evolution of the transcriptional regulator Stp15 led to reprogrammed gene transcription that conferred increased ethanol tolerance and conversion of glucose to ethanol in yeast [31].

\section{Adaptive mechanisms of evolutionary engineered cells}

Although extreme environmental or intracellular stressors often lead to cell death, those stresses that do not exceed a certain threshold are counterbalanced by rapid first-line protective mechanisms that confer survival [5] (Fig. 1B). Such responses can re-establish homeostasis and maintain viability by changes in metabolism, gene expression, cell-cycle progression, protein homeostasis, cytoskeletal organization, vesicular trafficking, and/or enzyme activity [32]. However, if a stress persists over time, cells often induce second-line adaptive mechanisms to promote genetic changes to maximize survival under continuous exposure [6]. These second-line adaptive responses need longer time to implement than the initial mechanisms. Therefore, in vitro evolution is employed to study the mechanism(s) in the laboratory in a feasible time-frame [33]. These adaptive strategies for the cell include mutation, gene amplification, transposition, multisite heterozygosity, mosicism (i.e., multiple sets of genetically different chromosomes), aneuploidy, polyploidy, and mistranslation. Many advances in bioinformatics and highthroughput genomic and proteomic analysis has allowed the identification and understanding of the molecular mechanisms behind stress-induced cellular evolution [34].

Epigenetic changes have also played a critical role in the adaptive response of yeast to stresses. Such epigenetic mechanisms allow rapid, reversible, and durable adaptations through histone or DNA modifications that alter the transcription, chromatin structure, nuclear organization, or pre-mRNA processing [35]. Also, prionmediated regulation of protein state may contribute as triggers for adaptation without direct genetic change [36]. Although epigenetic regulation is important for both first- and second-line adaptive mechanisms and well established by the analytic approaches [e.g., chromatin immunoprecipitation (ChIP)-seq, ChIp-chip, etc.], the selection of suitable targets for epigenetic modifications and high material cost of experiments limits epigenetic analysis.

\section{In vitro evolution-based new approach}

Evolutionary engineering is a useful strategy for yeast cells to adapt to the stress of genetic defects or environmental changes. Most of these adaptations are genetic 
variations in the expression of enzymes introduced by evolutionarily-conserved mechanisms. These mechanisms include higher rates of transcription that causes higher mutation frequencies due to promoting errorprone DNA polymerase activity, overwhelming the transcription-coupled DNA repair, aneuploidy stress, and error-prone nonhomologous end-joining DNA-repair pathway [37-40].

An example of a beneficial gene mutation is the loss of Ulp2 small ubiquitin-like modifier (SUMO) protease, which is involved in transcriptional regulation and chromosome cohesion [41-43]. In response to the acute loss of the Ulp2 enzyme, yeast cells undergo rapid induction of adaptive aneuploidy that counters the dysregulated SUMO system through the increased dosage of three genes CCR4, CLN3, and CCW12, and a cluster of small nucleolar RNA (snoRNA) genes, SNR61, SNR55, and SNR57 [44-46]. With aneuploidy being deleterious to cell fitness [47], evolution over many cell generations results in chromosomal duplications being eliminated and creates favorable mutations in SUMO-ligating enzymes, Ubc9, Uba2, or Aos1, which reduce SUMO conjugation and suppress the growth defects of $u l p 2 \Delta$ cells [45]. Another case is the long-term exposure of yeast to heat or high $\mathrm{pH}$ that triggers advantageous gene mutations and alterations in gene expression [16].

Identification of the advantageous genetic change from in vitro evolution constitutes one of the greatest merits. This fascinating approach explores what the genetic manipulation is required to overcome the specific stressful conditions and can further suggests targets for therapy of human genetic diseases and cancers. Also, in vitro evolutionary engineering establishes new relationships between different cellular pathways. In the end, this strategy can still offer many insights for industrial, medical, and academic applications.

\section{Discussion}

Yeast evolutionary engineering method is widely and progressively used in the industrial applications to improve production of biosynthetic compounds. Recently, rapid advances in sequencing and gene-editing technologies have expanded the field of evolutionary engineering using yeast cells and therefore it enables to identify beneficial mutations and provide insight on the adaptive mechanisms [10, 11, 48, 49]. Furthermore, this strategy is also applicable to studying human diseases. Overtaking the culture of diverse cell lines often leads to appear beneficial mutations to adapt to specific culture conditions [50-54]. Therefore, this is a future-oriented research field and will offer a promising candidate for human gene therapy in the future.

\section{Acknowledgments}

This work was supported by a National Research Foundation of Korea (NRF) grant funded by the Korean government (MSIT) (no. 2020R1C1C1009367).

\section{Conflict of Interest}

The authors have no financial conflicts of interest to declare.

\section{References}

1. Borodina I, Nielsen J. 2014. Advances in metabolic engineering of yeast Saccharomyces cerevisiae for production of chemicals. Biotechnol. J. 9: 609-620.

2. Padkina MV, Sambuk EV. 2018. Prospects for the application of yeast display in biotechnology and cell biology (Review). Appl. Biochem. Microbiol. 54: 337-351.

3. Mans R, Daran JMG, Pronk JT. 2018. Under pressure: evolutionary engineering of yeast strains for improved performance in fuels and chemicals production. Curr. Opin. Biotechnol. 50: 47-56.

4. Portnoy VA, Bezdan D, Zengler K. 2011. Adaptive laboratory evolution - harnessing the power of biology for metabolic engineering. Curr. Opin. Biotechnol. 22: 590-594.

5. Fulda S, Gorman AM, Hori O, Samali A. 2010. Cellular stress responses: cell survival and cell death. Int. J. Cell Biol. 2010: 214074.

6. Ryu HY, Ahn SH, Hochstrasser M. 2020. SUMO and cellular adaptive mechanisms. Exp. Mol. Med. 52: 931-939.

7. Dragosits M, Mattanovich D. 2013. Adaptive laboratory evolution - principles and applications for biotechnology. Microb. Cell Fact. 12: 64.

8. Lang Gl, Botstein D, Desai MM. 2011. Genetic variation and the fate of beneficial mutations in asexual populations. Genetics 188 : 647-661.

9. Gonzalez A, Bell G. 2013. Evolutionary rescue and adaptation to abrupt environmental change depends upon the history of stress. Philos Trans. R Soc. Lond B Biol. Sci. 368: 20120079.

10. Sonderegger M, Sauer U. 2003. Evolutionary engineering of Saccharomyces cerevisiae for anaerobic growth on xylose. Appl. Environ. Microbiol. 69: 1990-1998.

11. Kuyper $M$, Toirkens $M J$, Diderich JA, Winkler AA, van Dijken JP, Pronk JT. 2005. Evolutionary engineering of mixed-sugar utilization by a xylose-fermenting Saccharomyces cerevisiae strain. 
FEMS Yeast Res. 5: 925-934.

12. Wisselink HW, Toirkens MJ, Wu Q, Pronk JT, van Maris AJA. 2009. Novel Evolutionary engineering approach for accelerated utilization of glucose, xylose, and arabinose mixtures by engineered Saccharomyces cerevisiae strains. Appl. Environ. Microbiol. 75: 907914.

13. Daran-Lapujade P, Daran JM, van Maris AJA, de Winde JH, Pronk JT. 2009. Chemostat-based micro-array analysis in baker's yeast. Adv. Microb. Physiol. 54: 257-311.

14. Novick A, Szilard L. 1950. Description of the chemostat. Science 112: 715-716.

15. Selmecki AM, Maruvka YE, Richmond PA, Guillet M, Shoresh N, Sorenson AL, et al. 2015. Polyploidy can drive rapid adaptation in yeast. Nature 519: 349-352.

16. Yona AH, Manor YS, Herbst RH, Romano GH, Mitchell A, Kupiec $M$, et al. 2012. Chromosomal duplication is a transient evolutionary solution to stress. Proc. Natl. Acad. Sci. USA 109: 21010-21015.

17. Serero A, Jubin C, Loeillet S, Legoix-Ne P, Nicolas AG. 2014. Mutational landscape of yeast mutator strains. Proc. Natl. Acad. Sci. USA 111: 1897-1902.

18. Solis-Escalante $D$, van den Broek M, Kuijpers NGA, Pronk JT, Boles $E$, Daran JM, et al. 2015. The genome sequence of the popular hexose-transport-deficient Saccharomyces cerevisiae strain EBY.VW4000 reveals LoxP/Cre-induced translocations and gene loss. FEMS Yeast Res. 15: fou004.

19. Shen Y, Stracquadanio G, Wang Y, Yang K, Mitchell LA, Xue YX, et al. 2016. SCRaMbLE generates designed combinatorial stochastic diversity in synthetic chromosomes. Genome Res. 26: 36-49.

20. Finney-Manchester SP, Maheshri N. 2013. Harnessing mutagenic homologous recombination for targeted mutagenesis in vivo by TaGTEAM. Nucleic Acids Res. 41: e99.

21. Nishida K, Arazoe T, Yachie N, Banno S, Kakimoto M, Tabata M, et al. 2016. Targeted nucleotide editing using hybrid prokaryotic and vertebrate adaptive immune systems. Science 353: aaf8729.

22. Attfield PV. 1997. Stress tolerance: The key to effective strains of industrial baker's yeast. Nat. Biotechnol. 15: 1351-1357.

23. Randez-Gil F, Sanz P, Prieto JA. 1999. Engineering baker's yeast: room for improvement. Trends Biotechnol. 17: 237-244.

24. Schulze U, Liden G, Nielsen J, Villadsen J. 1996. Physiological effects of nitrogen starvation in an anaerobic batch culture of Saccharomyces cerevisiae. Microbiology 142: 2299-2310.

25. Sillje HHW, Paalman JWG, ter Schure EG, Olsthoorn SQB, Verkleij AJ, Boonstra J, et al. 1999. Function of trehalose and glycogen in cell cycle progression and cell viability in Saccharomyces cerevisiae. J. Bacteriol. 181: 396-400.

26. Mager WH, Ferreira PM. 1993. Stress response of yeast. Biochem. J. 290: 1-13.

27. Singer MA, Lindquist S. 1998. Thermotolerance in Saccharomyces cerevisiae: the Yin and Yang of trehalose. Trends Biotechnol. 16: 460-468.

28. Mensonides $\mathrm{FI}$, Schuurmans JM, Teixeira de Mattos MJ, Hellingwerf $\mathrm{KJ}$, Brul S. 2002. The metabolic response of Saccharomyces cerevisiae to continuous heat stress. Mol. Biol. Rep. 29: 103-106.
29. Parada G, Acevedo F. 1983. On the relation of temperature and RNA content to the specific growth rate in Saccharomyces cerevisiae. Biotechnol. Bioeng. 25: 2785-2788.

30. Teunissen A, Dumortier F, Gorwa MF, Bauer M, Tanghe A, Loiez A, et al. 2002. Isolation and characterization of a freeze-tolerant diploid derivative of an industrial baker's yeast strain and its use in frozen doughs. Appl. Environ. Microbiol. 68: 4780-4787.

31. Alper H, Moxley J, Nevoigt E, Fink GR, Stephanopoulos G. 2006. Engineering yeast transcription machinery for improved ethanol tolerance and production. Science 314: 1565-1568.

32. Cipponi A, Thomas DM. 2014. Stress-induced cellular adaptive strategies: ancient evolutionarily conserved programs as new anticancer therapeutic targets. Bioessays 36: 552-560.

33. Rosenberg SM, Thulin C, Harris RS. 1998. Transient and heritable mutators in adaptive evolution in the lab and in nature. Genetics 148: $1559-1566$.

34. Oud B, van Maris AJA, Daran JM, Pronk JT. 2012. Genome-wide analytical approaches for reverse metabolic engineering of industrially relevant phenotypes in yeast. FEMS Yeast Res. 12: 183-196.

35. Fabrizio P, Garvis S, Palladino F. 2019. Histone methylation and memory of environmental stress. Cells. 8: 339.

36. Westergard L, True HL. 2014. Wild yeast harbour a variety of distinct amyloid structures with strong prion-inducing capabilities. Mol. Microbiol. 92: 183-193.

37. Datta A, Jinks-Robertson S. 1995. Association of increased spontaneous mutation rates with high levels of transcription in yeast. Science 268: 1616-1619.

38. Shor E, Fox CA, Broach JR. 2013. The yeast environmental stress response regulates mutagenesis induced by proteotoxic stress. PLoS Genet. 9: e1003680.

39. Sheltzer JM, Blank HM, Pfau SJ, Tange Y, George BM, Humpton TJ, et al. 2011. Aneuploidy drives genomic instability in yeast. Science 333: 1026-1030.

40. Heidenreich E, Novotny R, Kneidinger B, Holzmann V, Wintersberger U. 2003. Non-homologous end joining as an important mutagenic process in cell cycle-arrested cells. EMBO J. 22: 22742283.

41. Hickey CM, Wilson NR, Hochstrasser M. 2012. Function and regulation of SUMO proteases. Nat. Rev. Mol. Cell Biol. 13: 755-766.

42. Ryu HY, Su D, Wilson-Eisele NR, Zhao DJ, Lopez-Giraldez F, Hochstrasser M. 2019. The Ulp2 SUMO protease promotes transcription elongation through regulation of histone sumoylation. EMBO J. 38: e102003.

43. Stephens AD, Snider CE, Bloom K. 2015. The SUMO deconjugating peptidase Smt4 contributes to the mechanism required for transition from sister chromatid arm cohesion to sister chromatid pericentromere separation. Cell Cycle 14: 2206-2218.

44. Ryu HY, Wilson NR, Mehta S, Hwang SS, Hochstrasser M. 2016. Loss of the SUMO protease Ulp2 triggers a specific multichromosome aneuploidy. Genes Dev. 30: 1881-1894.

45. Ryu HY, Lopez-Giraldez F, Knight J, Hwang SS, Renner C, Kreft SG, et al. 2018. Distinct adaptive mechanisms drive recovery from 
aneuploidy caused by loss of the Ulp2 SUMO protease. Nat. Commun. 9: 5417.

46. Ryu HY, Hochstrasser M. 2017. Adaptive aneuploidy counters a dysregulated SUMO system. Cell Cycle. 16: 383-385.

47. Torres EM, Sokolsky T, Tucker CM, Chan LY, Boselli M, Dunham MJ, et al. 2007. Effects of aneuploidy on cellular physiology and cell division in haploid yeast. Science 317: 916-924.

48. Cakar ZP, Seker UOS, Tamerler C, Sonderegger M, Sauer U. 2005. Evolutionary engineering of multiple-stress resistant Saccharomyces cerevisiae. FEMS Yeast Res. 5: 569-578.

49. van Maris AJA, Geertman JMA, Vermeulen A, Groothuizen MK, Winkler AA, Piper MDW, et al. 2004. Directed evolution of pyruvate decarboxylase-negative Saccharomyces cerevisiae, yielding a C-2-independent, glucose-tolerant, and pyruvate-hyperproducing yeast. Appl. Environ. Microbiol. 70: 159-166.

50. Draper JS, Moore HD, Ruban LN, Gokhale PJ, Andrews PW. 2004.
Culture and characterization of human embryonic stem cells. Stem Cells Dev. 13: 325-336.

51. Mitalipova MM, Rao RR, Hoyer DM, Johnson JA, Meisner LF, Jones $\mathrm{KL}$, et al. 2005. Preserving the genetic integrity of human embryonic stem cells. Nat. Biotechnol. 23: 19-20.

52. Inzunza J, Sahlen S, Holmberg K, Stromberg AM, Teerijoki H, Blennow E, et al. 2004. Comparative genomic hybridization and karyotyping of human embryonic stem cells reveals the occurrence of an isodicentric $X$ chromosome after long-term cultivation. Mol. Hum. Reprod. 10: 461-466.

53. Maitra A, Arking DE, Shivapurkar N, Ikeda M, Stastny V, Kassauei $\mathrm{K}$, et al. 2005. Genomic alterations in cultured human embryonic stem cells. Nat. Genet. 37: 1099-1103.

54. Olariu V, Harrison NJ, Coca D, Gokhale PJ, Baker D, Billings S, et al. 2010. Modeling the evolution of culture-adapted human embryonic stem cells. Stem Cell Res. 4: 50-56. 